\title{
Antimicrobial Finishing of Denim Fabrics with Herbal Extracts
}

\author{
Sumithra $\mathbf{M}^{1, *}$, Vasugi Raaja $\mathbf{N}^{2}$ \\ ${ }^{1}$ Department of Costume Design and Fashion, PSG College of Arts and Science, Coimbatore \\ ${ }^{2}$ Department of Textiles and Clothing, Avinashilingam Institute for Home Science and Higher Education for Women, Coimbatore \\ *Corresponding author: mithrasumi6@rediffmail.com
}

Received February 26, 2014; Revised February 27, 2014; Accepted February 27, 2014

\begin{abstract}
Aim: Herbs play a significant role in pharmaceutical industries as life saving drugs. This calls for the discovery of new antimicrobial compounds with diverse chemical structures and novel mechanisms of action. The present study focuses on imparting antimicrobial finish to the denim fabric using natural herbal extracts. Methodology: Three herbs, Ricinus communis, Senna auriculata and Euphorbia hirta were screened for their antimicrobial efficiency by finishing the methanolic extracts of these herbs on the denim fabric by qualitative test method EN ISO 20645. The combinatorial antimicrobial efficiency (1:3:2) of these extracts were studied and confirmed quantitatively by performing AATCC 100 test method. The antifungal activity was tested according to AATCC 30 test method. Results: The combinatorial ratio (1:3:2) showed 98\% bacterial reduction against Escherichia coli and 99\% against Staphylococcus aureus. Same ratio also showed 100\% mycelial reduction against Aspergillus niger. Conclusion: The combinatorial antibacterial activities of the selected three herbs showed excellent results compared to the individual finishing.
\end{abstract}

Keywords: herbal extraction, denim fabric, antimicrobial textile, quantitative assay, agar diffusion

Cite This Article: Sumithra M, and Vasugi Raaja N, "Antimicrobial Finishing of Denim Fabrics with Herbal Extracts.” American Journal of Medical and Biological Research, vol. 2, no. 1 (2014): 26-30. doi: 10.12691/ajmbr-2-1-5.

\section{Introduction}

The consumers are demanding textile products with higher performances, even in the "traditional" clothing and home textiles areas. In fact, significant product differentiation in the area of textiles can be achieved by high performance properties, in parallel with visual appearance. Some of these properties were developed mainly for "protective" clothing but nowadays they are often present in functional textiles used for "normal" clothing. Many fabric producers are devoting more and more attention to try to put into the market products with new effects that can represent an important added value. Denim garments has an evergreen demand among the consumers globally, as it is the only fabric that can be worn during any season and it is both fashion and performance driven as well. Traditionally denim was made as $14-16$ ounce twill woven fabric using cotton ring spun indigo dyed yarn. Recently many variations and adaptations of denim have been introduced in the market that are woven, knitted and dyed. Apart from the innovations in fabrication of denim, value added finishing to garments such as fragrance finish, anti-microbial finish, antifungal adds up more value to the product in the current market scenario. Over the years, many different denim fabric treatments have been introduced, including prewashed, stone-washed, sandblasted, and vintage but hardly any attempt has been made for a functional finish [1].
Functional properties can be defined as all the effects that are beyond the pure aesthetic and decorative functions. They include a large range of properties that in some cases can be also classified as "smart properties", which means that they grant to the textiles the capacity of acting according to an external stimulation. The scope for denim wear is increasing tremendously every year and its worldwide market share has increased unpredictably in the last few decades. Consumers' needs and wants are finetuned towards the latest developments and new styles; they are also aware of special finishes and process treatments given to the garment to make them eco-friendly and user friendly. Microorganisms are part of our daily lives. The entire human machine would not function without these multitudes of little helpers. Our skin, too, is infested with countless numbers of microorganisms. During normal course of living, our skin comes in contact with the soil and hence clothing is seeded with different microbes. Clothing and textile serve as carriers and also a good media for pathogenic, odor generating bacteria, moulds and fungi. Natural fibres like cotton are more susceptible to microbial attack than man-made fibres. A major factor that has stimulated interest in antimicrobial finishes has been the current vogue that promotes a healthier and physically active life style. In addition, textile consumers are now becoming much more aware of the detrimental effects that microorganisms have upon textiles and upon human hygiene. Due to increasing market interest, a growing number of companies launched their textile products with antimicrobial finishes [2]. 
Recently, an awareness of general sanitation, contact disease transmission, and personal protection has led to the development of antibacterial fibers to protect wearers against the spread of bacteria and diseases rather than to protect the quality and durability of the textiles [3]. Most of the processes to create antibacterial fibers entail the attachment of biocidal or bacteriostatic agents to the fabric surface, for example, N-halamine, enzyme, quaternary ammonium salt, chitosan, or zinc oxide. Antimicrobial finish is applied to textile materials with a view to protect the wearer and textile substrate itself. Antimicrobial finish provides the various benefits of controlling the infestation by microbes protect textiles from staining, discoloration, and quality deterioration and prevents the odor formation. Anti-microbial agents can be applied to the textile substrates by exhaust, pad-dry-cure, coating, spray and foam techniques. The application of the finish is now extended to textiles used for outdoor, healthcare sector, sports and leisure. Herbal products seem to possess moderate efficacy with no or less toxicity and are less expensive as compared with synthetic drugs. Many plants and plants-derived products have been shown to possess potent antibacterial activity $[4,5,6]$.

Plants contain phytochemicals that have effects on the body. Herbs have long been used as the basis of traditional Chinese herbal medicine, with usage dating as far back as the first century $\mathrm{CE}$ and far before. With increasing frequency, modern medicine directs attention to natural products with antimicrobial activity and their use in clinical practice. The major arguments for implementing natural products such as honey, Aloe vera or curcumin are the low cost and absence of antimicrobial resistance risk in comparison with conventional wound-care products [7]. Natural medicinal products have been used for millennia for the treatment of multiple ailments. Although many have been suppressed by conventional pharmaceutical approaches, there is currently resurgence in interest in the use of natural products by the general public, which forms the basis of a worldwide, multi-million dollar major commercial industry. In the present work, a novel idea of imparting antimicrobial property to the denim fabric using herbal extracts was carried out.

\section{Materials and Methods}

\subsection{Collections of Herbal plants}

The herbal plants such as Ricinus communis, Senna auriculata and Euphorbia hirta were collected from in and around Coimbatore district, Tamil Nadu, South - east coast of India. They were identified and authenticated by the department of Botany, PSG College of arts and science, Coimbatore.

\subsection{Preparation of Herbal Extracts}

The collected plant parts (leaves) were dried within a temperature range of $100-140{ }^{\circ} \mathrm{F}$ as they cannot be stored without drying to avoid breakdown of important compounds and contamination by microorganisms. Garbling, the separation of that portion of the plant to be used from other parts of the plants, dirt and other extraneous matter was done manually by hand. Grinding or mincing of the leaves was carried out in a mixie. The fine powder obtained after grinding was used for extraction. Each $100 \mathrm{~g}$ of the powdered plant material was refluxed in a Soxhlet apparatus in $1000 \mathrm{ml}$ of $80 \%$ methanol. After overnight incubation, the supernatant was filtered through Whatman no.1 filter paper and the filtrate was dried to evaporate the organic solvent at room temperature.

\subsection{Finishing of the Herbal Extracts on the Denim Fabric}

The denim fabric purchased from K.G. Denim Ltd, Coimbatore was used for the present study. The fabric sample was given a primary wash with distilled water, airdried and then used for herbal finishing. The fabric was finished with herbal extract by dip method. The fabric was immersed in the methanolic extract for 30 mins and then air-dried. The finished fabric was used for the antibacterial assessment using standard bacterial strains.

\subsection{Antibacterial Assessment of the Finished Fabric - EN ISO 20645 Test Method}

In vitro antibacterial activity of the finished fabric was determined by test method using sterile Bacteriostasis agar obtained from Himedia (Mumbai). The agar plates were prepared by pouring $15 \mathrm{ml}$ of media into sterile Petri plates. The plates were allowed to solidify for 5 minutes and $0.1 \%$ inoculum suspension of Staphylococcus aureus (ATCC 6538), a Gram-positive organism and Escherichia coli (ATCC 8739), a Gram-negative organism were swabbed uniformly and the inoculum was allowed to dry for 5 minutes. The herbal extract finished denim fabric with the diameter of $20 \pm 2 \mathrm{~mm}$ was placed on the surface of medium and the plates were kept for incubation at $37^{\circ} \mathrm{C}$ for 24 hours. At the end of incubation, zone of inhibition formed around the fabric was measured in millimeter and recorded.

\subsection{Selection of Best Herbal Combination}

From the preliminary screening, the three selected herbal extracts with antibacterial activity were mixed in various combinations and screened for their combinatorial antibacterial property by EN ISO 20645 test method. Various proportions of the selected herbs were used in the combinatorial analysis and the antibacterial activities of the herbal combinations were studied.

\subsection{Evaluation of Antibacterial Activity by Quantitative Assay (AATCC 100)}

The antibacterial activity was quantitatively evaluated against Staphylococcus aureus (ATCC 6538), a Grampositive organism and Escherichia coli (ATCC 8739), a Gram-negative organism in accordance with AATCC 100 test method. Fabric samples of $4.8 \pm 0.1 \mathrm{~cm}$ diameter were placed in a $50 \mathrm{ml}$ conical flask with $0.5 \mathrm{ml}$ of bacterial inoculums. After incubation over contact periods of $24 \mathrm{hr}$, the solution was serially diluted. The diluted solution was plated on a nutrient agar and incubated for $24 \mathrm{hr}$ at $37 \pm$ $2^{\circ} \mathrm{C}$. Colonies of bacteria recovered on the agar plate were counted and the percent reduction of bacteria (R) was calculated using the following equation:

$$
\mathrm{R}(\%)=(\mathrm{B}-\mathrm{A}) \times 100 / \mathrm{B}
$$


where A is the number of bacterial colonies from treated specimen after inoculation over 24 hours contact period and $\mathrm{B}$ is the number of bacterial colonies from untreated control specimen after inoculation over 24 hours contact time.

\subsection{Analysis of Antifungal Activity by Agar Diffusion (AATCC 30)}

The test strain used in this analysis was Aspergillus niger. An inoculum of $1.0 \mathrm{ml}$ was evenly distributed over the surface of the agar. The fabric discs were pre wetted (not rubbed or squeezed) in water containing $0.05 \%$ of a non-ionic wetting agent (triton X-100) and placed on the agar surface. The inoculum of $0.2 \mathrm{ml}$ was distributed evenly over each disc by means of a sterile pipette. All the specimens were incubated at a temperature of $28^{\circ} \mathrm{C}$ for seven days. At the end of the incubation period, the percentage of the surface area of the disc covered with the growth of the fungus was reported by measuring the zone of mycostasis (mm) and by observing visually using a microscopic (40X).

\section{Results and Discussion}

\subsection{Collection of Herbs and Preparation of Herbal Extracts}

The herbs were collected from in and around Coimbatore district, identified and authenticated by the department of Botany, PSG College of arts and science,
Coimbatore. The plant parts were cleaned, processed and dried. The dried parts were powdered in mixie and the fine powder was extracted using methanol. The methanolic extract was filtered and the filtrate was dried to evaporate the solvent. The extract was used for finishing the denim fabric. The medicinal plants and their specific parts used for the extraction are listed in the Table 1.

Table 1. PLANTS USED IN THE PRESENT STUDY

\begin{tabular}{|c|c|c|c|}
\hline S. No & $\begin{array}{c}\text { Scientific } \\
\text { Name }\end{array}$ & Parts used & $\begin{array}{c}\text { Common Name } \\
\text { (English) }\end{array}$ \\
\hline 1 & $\begin{array}{c}\text { Ricinus } \\
\text { communis }\end{array}$ & Leaves & Castor oil plant \\
\hline 2 & $\begin{array}{c}\text { Senna } \\
\text { auriculata }\end{array}$ & Leaves & Ranawara \\
\hline 3 & Euphorbia hirta & $\begin{array}{c}\text { Leaves, Stem and } \\
\text { Flower }\end{array}$ & Asthma weed \\
\hline
\end{tabular}

\subsection{Determination of the antibacterial Activity of the Finished Fabric}

The finished fabric was assessed for the antibacterial activity by EN ISO 20645 test method against Escherichia coli and Staphylococcus aureus. The results of the table showed that the methanolic extract of the herbs were efficient in providing antibacterial activity to the finished fabric. Of the three herbs used, the methanolic extract of Senna auriculata was found to give maximum antibacterial activity (25 $\mathrm{mm}$ zone of inhibition against Escherichia coli and $29 \mathrm{~mm}$ against Staphylococcus aureus) compared to the other two herbs (Table 2).

Table 2. ANTIBACTERIAL ACTIVITY OF THE HERBAL EXTRACT FINISHED FABRIC - EN ISO 20645

\begin{tabular}{|c|c|c|c|}
\hline \multirow{2}{*}{ S. No. } & Fabric treatment & \multicolumn{2}{|c|}{ Antibacterial activity Zone of Inhibition in mm) } \\
\cline { 3 - 4 } & & E. coli & 0 S. aureus \\
\hline A & Denim fabric finished with methanolic extract of Ricinus communis (A) & 26 \\
\hline B & Denim fabric finished with methanolic extract of Senna auriculata (B) & 25 \\
\hline C & Denim fabric finished with methanolic extract of Euphorbia hirta (C) & 24 & 27 \\
\hline
\end{tabular}

0* - No bacterial growth beneath the test fabric.

The scientist [8] reported that the methanol extract of seeds of Helianthus annuus showed low activity (14 mm) against Bacillus subtilis, maximum activity $(23 \mathrm{~mm})$ against Proteus vulgaris and inactive against the rest of tested organisms. All extracts of Helianthus annuus were inactive against Aspergillus niger and Candida albicans. The methanol extract of bulbs of Allium cepa exhibited maximum activity against Bacillus subtilis (23 mm), Proteus vulgaris (20 mm), Pseudomonas aeruginosa (23 $\mathrm{mm}$ ) and inactive against Staphylococcus aureus, Escherichia coli, Salmonella typhi and against Aspergillus niger and Candida albicans. The methanol extract of the leaves of Azadirachta indica exhibited pronounced activity (28 mm) against Bacillus subtilis, high activity (18 mm) against the Gram-positive Staphylococcus aureus and the Gram-negative organisms Proteus vulgaris, (20 $\mathrm{mm})$ against Salmonella typhi, low activity $(14 \mathrm{~mm})$ against Pseudomonas aeruginosa and inactive against Escherichia coli. Antibacterial activity of crude extracts of $E$. hirta was evaluated by measuring the diameters of zones of growth inhibition on some members of the enterobacteriaceae. All the test organisms were susceptible to E. hirta extracts though to varying degrees.
The results show that increase in concentration of extract increased the zone of growth inhibition of some of the microorganisms. The extract did not inhibit the growth of Salmonella typhi at any of the concentrations administered. The highest zone of growth inhibition was exhibited by the extract on Staphylococcus aureus giving a zone diameter of $13.5 \mathrm{~mm}$ when administered at $250 \mathrm{mg} / \mathrm{ml}$ concentration. Only the $200 \mathrm{mg} / \mathrm{ml}$ and $250 \mathrm{mg} / \mathrm{ml}$ concentrations had effects on Bacillus subtilis while at 50 $\mathrm{mg} / \mathrm{ml}$ the extract had no effect on $E$. coli and Pseudomonas aeruginosa. The lowest zone of growth inhibition was observed with $200 \mathrm{mg} / \mathrm{ml}$ concentration of the extract on $B$. subtilis, which gave a zone of inhibition measuring $5.6 \mathrm{~mm}$ [9].

\subsection{Selection of best herbal combination}

The antibacterial activities of the three herbal extracts were studied individually and the results showed maximum antibacterial activity. The antibacterial efficiency of the denim fabric finished with the combination of the herbal extracts was studied and the results are presented in Table 3. 
Table 3. COMBINATORIAL ANTIBACTERIAL ACTIVITY OF THE HERBAL EXTRACTS ON THE DENIM FABRIC

\begin{tabular}{|c|c|c|c|}
\hline \multirow{2}{*}{ S. } & \multirow{2}{*}{$\begin{array}{c}\text { Herbal combination } \\
\text { (Ricinus communis: Senna } \\
\text { auriculata: } \text { Euphorbia hirta) }\end{array}$} & \multicolumn{2}{|c|}{$\begin{array}{c}\text { Antibacterial activity } \\
\text { Zone of Inhibition (mm) }\end{array}$} \\
\cline { 3 - 4 } & $1: 1: 1$ & E. coli & S. aureus \\
\hline 1. & $1: 2: 1$ & 0 & 0 \\
\hline 2. & $2: 1: 1$ & $0^{*}$ & 23 \\
\hline 3. & $1: 1: 2$ & 23 & $0 *$ \\
\hline 4. & $2: 2: 1$ & 0 & 24 \\
\hline 5. & $1: 2: 2$ & 24 & 23 \\
\hline 6. & $2: 1: 2$ & $0 *$ & 25 \\
\hline 7. & $3: 1: 2$ & 24 & 24 \\
\hline 8. & $1: 3: 2$ & 24 & 27 \\
\hline 9. & $1: 2: 3$ & 26 & 30 \\
\hline 10. & & 25 & 26 \\
\hline $1 \cdot 3 \cdot 2$ & & & \\
\hline
\end{tabular}

1:3:2 combinations was selected.

From the results of the table, the best herbal combination was selected to be 1:3:2 of Ricinus communis, Senna auriculata and Euphorbia hirta respectively. The work of scientist [10] showed that the extracts from basil, clove, guava, jambolan, lemon balm, pomegranate, rosemary and thyme presented antimicrobial activity to at least one of the tested microorganisms. The extracts from clove and jambolan presented the highest activities, i. e., they were able to inhibit 9 (64.2\%) and 8 (57.1\%) types of microorganisms of interest, respectively. Moreover, they also had the highest activity rate against antibiotic resistant bacteria, which was $83.3 \%$ (Figure 1). On the other hand, the extracts from sage and yarrow did not show any anti-microbial activity.

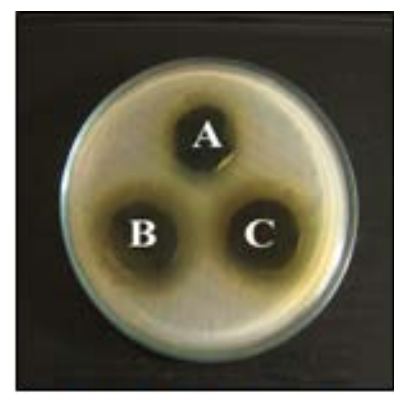

Escherichia coli

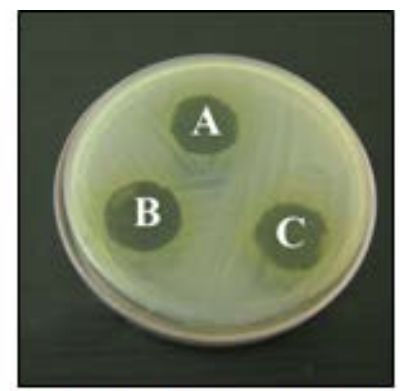

Staphylococcus aureus
Figure 1. Antibacterial activity of the herbal extract finished fabric. Assessment was made against two test bacterial cultures $E$. coli and $S$. aureus

\subsection{Antibacterial Assay of the Fabric by Quantitative Method (AATCC 100)}

The fabric finished with the effective herbal combination was tested for its antibacterial activity by AATCC 100 test method and the results are presented in Table 4 and Figure 2.

Table 4. ANTIBACTERIAL ACTIVITY ASSESSMENT BY AATCC 100

\begin{tabular}{|c|c|c|c|}
\hline \multirow{2}{*}{ S. No. } & Fabric samples & \multicolumn{2}{|c|}{$\begin{array}{c}\text { Antibacterial activity } \\
\text { (Bacterial reduction in \%) }\end{array}$} \\
\cline { 3 - 4 } & & E. coli & S. aureus \\
\hline 1 & $\begin{array}{c}\text { Herbal extract finished } \\
\text { denim fabric }\end{array}$ & 98 & 99 \\
\hline
\end{tabular}

Plant extracts of Senna auriculata have inhibitory effects on Pseudomonas aeruginosa, Staphylococcus aureus and Bacillus subtilis. Their zones of inhibition are more than that of the control drugs against them. E. coli is found to be little resistant at lower concentrations, but at higher concentration, the antimicrobial activity is found to be at par with the control drugs. Senna auriculata and Indigofera tinctoria have good microbial activities against all the test microbes at all concentrations and their zones of inhibition are also sufficiently high. These two plants could also be further tested against other microbes too [11]. The Ricinus communis showed good activity against dermatophytic and pathogenic bacterial strains Streptococcus progenies, Staphylococcus aureus as well as Klebsiella pneumoniae, Escherichia coli [12].
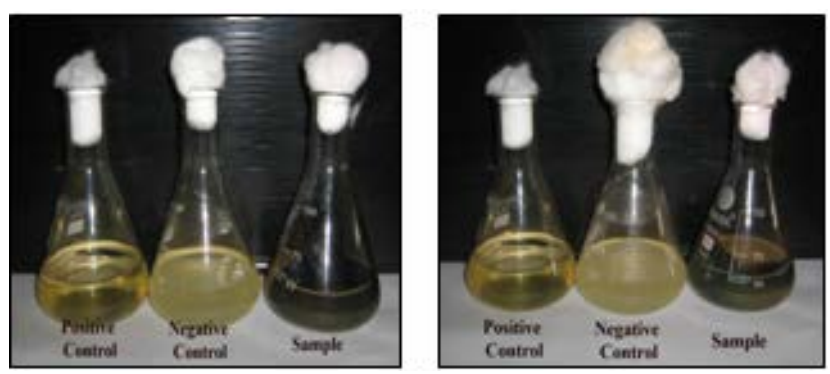

Figure 2. Antibacterial assessment of the denim fabric. Assessment was made against two test bacterial cultures $E$. coli and $S$. aureus

\subsection{Antifungal Activity of the Finished Fabric Sample}

The antifungal activity of the finished fabric was tested by AATCC 30 test method against Aspergillus niger test organism. The results of the untreated and herbal extract treated fabrics are presented below in Table 5 and Figure 3.

Table 5. ANTIFUNGAL ACTIVITY OF THE HERBAL EXTRACT FINISHED DENIM FABRIC

\begin{tabular}{|c|c|c|}
\hline S. No. & Sample & $\begin{array}{c}\text { Aspergillus niger } \\
\text { (Mycelial reduction in \%) }\end{array}$ \\
\hline 1 & Untreated fabric & 0 \\
\hline 2 & Herbal extract treated fabric & 100 \\
\hline
\end{tabular}

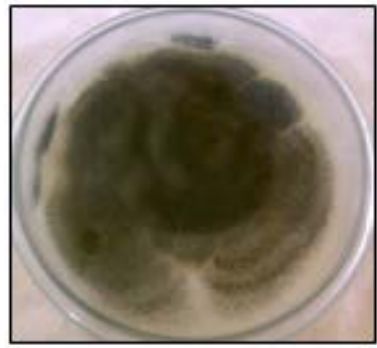

Untreated fabric

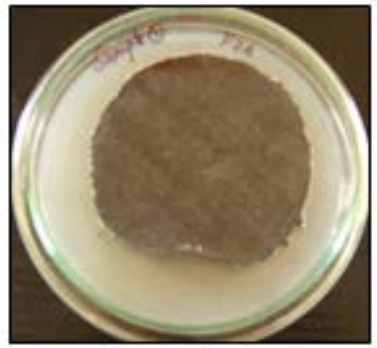

Treated fabric
Figure 3. Antifungal activity of the fabrics against Aspergillus niger

The results showed that compared to the untreated fabric, the treated fabric showed complete reduction of mycelial growth, thereby showing $100 \%$ antifungal activity. When the herbal extract finished denim fabric was subjected to washing, followed by assessment of antibacterial activity, the results showed that the denim fabric was not able to withstand the antibacterial activity 
even for 5 industrial washes. The hexane and methanol extracts $(200 \mathrm{mg} / \mathrm{ml})$ of roots of Ricinus communis showed good activity against pathogenic bacterial and fungal strains. Aqueous extracts showed no antimicrobial activity against any of the pathogens. Hexane extracts $(200 \mathrm{mg} / \mathrm{ml})$ showed prominent antimicrobial activity against Candida albicans and Aspergillus niger fungal strains. Methanol extracts $(200 \mathrm{mg} / \mathrm{ml})$ were found to be prominent against $E$. coli and Aspergillus niger [13]. Therefore, in order to increase the durability of the antimicrobial finish, microencapsulation and nanoencapsulation of the herbal extracts were adopted.

\section{Conclusion}

Approximately $80 \%$ of people in developing countries still rely on traditional medicines for their primary health care. This usually involves the use of plant ex-tracts. Medicinal plants usually constitute an important source of new and biologically active compounds. In the present study, the antimicrobial efficiency of three herbal extracts Ricinus communis, Senna auriculata and Euphorbia hirta were studied. The results showed promising use of these herbal extracts as source of antimicrobial finishing on denim fabric. The extract finished fabric showed maximum antibacterial activity against both Escherichia coli and Staphylococcus aureus and antifungal activity against Aspergillus niger. The combinatorial antibacterial activities of the selected three herbs were also studied and the results showed excellent results compared to the individual finishing. Further pharmacological and clinical studies are required to understand the mechanism and the actual efficacy of these herbal extracts in providing antimicrobial activity to the finished fabric.

\section{References}

[1] Vijayalakshmi, D and Ramachandran, T, "Isolates application of Multi-functional finishes on denim garments”, Daffodil
International University Journal of Science and Technology, Vol. 7, 2012. pp. 59-66.

[2] Thilagavathi, G., Rajendrakumar, K and Rajendran, R,” Development of antimicrobial textile finishes from plant species”, Indian J. Fibre Text Res., Vol. 30, 2005. pp. 430.

[3] Chun, DTW and Gamble, GR, "Using the reactive dye method to covalently attach antibacterial compound to cotton”, J. Cotton Sci. Vol. 11, 2007. pp. 154-158.

[4] Gupta, A., Upadhyay, NK., Sawhney, RC and Kumar, RA, "Polyherbal formulation accelerates normal and impaired diabetic wound healing”, Wound Rep Regen., Vol. 16, 2008. pp. 784-790.

[5] Shetty, S., Udupa, S and Udupa, L, "Evaluation of antioxidant and wound healing effects of alcoholic and aqueous extract of Ocimum sanctum linn in rats”, ECAM, Vol. 5, 2008. pp. 95-101.

[6] Phan, TT., Hughes, MA and Cherry, GW, "Enhanced proliferation of fibroblasts and endothelial cells treated with an extract of the leaves of Chromolaena odorata (Eupolin), an herbal remedy for treating wounds", Plast Reconstr Surg., Vol. 101, 1998. pp. 756765.

[7] Majtan, J, “1,2 Commentary Methylglyoxal - a Potential Risk Factor of Manuka Honey in Healing of Diabetic Ulcers”, eCAM Advance Access, Vol. 22, 2010. pp. 1-5.

[8] Yagoub, SO., Safi, SEHA., Ahmed, B., Magbol, AZE, "Antimicrobial activity of some medicinal plants against some gram positive, gram negative and fungi”, Phytotherapy research, Vol. 14, 2006. pp. 329-332.

[9] Ogueke, CC., Ogbulie, JN., Okoli, IC and Anyanwu, BN, "Antibacterial activities and toxicological potentials of crude ethanolic extracts of Euphorbia hirta”, Journal of American Science, Vol. 3, 2007. pp. 11-16.

[10] Nascimenta, GGF, Locatelli, J., Freitas, PC and Silva, GL, "Antibacterial activity of plant extracts and phytochemicals on antibiotic-resistant bacteria”, Brazilian Journal of Microbiology, Vol. 31, 2000. pp. 247-256.

[11] Selvakumar, S and Karunakaran, CM, "Antimicrobial efficacy of Senna auriculata, Pongamia glabra and Indigofera tinctoria against pathogenic microorganisms”, International Journal of Pharm. Tech Research, Vol. 2, 2010. pp. 2054-2059.

[12] Islam, T., Bakshi, H., Sam, S and Sharma, E, ”Assessment of antibacterial potential of leaves of Ricinus communis against pathogenic and dermatophytic bacteria”, International Journal of Pharma. Research and Development - Online. ISSN 0974-9446, 2010.

[13] Mathur, A., Verma, SK., Yousuf, S., Singh, SK., Prasad, KS and Dua, VK, "Antimicrobial potential of roots of Ricinus communis against pathogenic microorganisms", International Journal of Pharma and Bio Sciences, Vol. 2, 2011. pp. 545-548. 